\title{
Dynamic Properties Test and Constitutive Relation Study of Lightweight Aggregate Concrete under Uniaxial Compression
}

\author{
Zhiqing Zhao (iD) \\ School of Art and Architecture, Global Institute of Software Technology, Suzhou 215163, China \\ Correspondence should be addressed to Zhiqing Zhao; zzq18801581991@126.com
}

Received 25 October 2021; Revised 7 December 2021; Accepted 9 December 2021; Published 21 December 2021

Academic Editor: Antonio Caggiano

Copyright (c) 2021 Zhiqing Zhao. This is an open access article distributed under the Creative Commons Attribution License, which permits unrestricted use, distribution, and reproduction in any medium, provided the original work is properly cited.

\begin{abstract}
For the purpose of studying the dynamic properties of lightweight aggregate concrete, dynamic performance tests under uniaxial compression were conducted by considering 10 different strain rates ranging from $10^{-5} / \mathrm{s}$ to $10^{-1} / \mathrm{s}$, from which the stress-strain curves under various compressive loads were obtained. From the stress-strain curves, parameters including peak stress, peak strain, and elastic modulus of lightweight aggregate concrete, as well as the concrete failure mode, were determined and examined. By reviewing the relevant literature on ordinary concrete, the dynamic properties of lightweight aggregate concrete were analyzed accordingly. Meanwhile, by applying the dynamic elastoplastic damage constitutive model, the effect of dynamic rate on lightweight aggregate concrete was calculated. The experimental results showed that the damage mode of lightweight aggregate concrete under the static and dynamic strain rates belonged to shear failure, which is different from that of ordinary concrete (binding material failure). On the other hand, it was also found that the peak stress and elastic modulus of lightweight aggregate concrete could be increased by $54.48 \%$ and $28.75 \%$, respectively, with the increase of strain rate, suggesting that the loading strain rate has a stronger influence on lightweight aggregate concrete than on ordinary concrete. Based on the experimental data, both the peak stress and nondimensionalized elastic modulus are in linear relationship with the logarithm of the nondimensionalized strain rate. Moreover, the established constitutive model had been verified as an effective and reliable tool for simulating the dynamic rate effect of lightweight aggregate concrete.
\end{abstract}

\section{Introduction}

Nowadays, concrete has become one of the most widely used engineering materials worldwide because of its unique advantages. Due to the nonlinear and stochastic characteristics and dynamic efficiency of mechanical property, this material has long been studied by lots of scholars [1-3]. In recent years, lightweight aggregate concrete, as a novel type of concrete, has drawn great attention for its light weight, high strength, good thermal insulation, high fire resistance, and etc. Although this material has already been used in practical engineering projects such as Shinkansen in Japan, there is not yet any comprehensive research on its dynamic properties $[4,5]$. Analysis of the dynamic mechanical properties of concrete is of great significance to the study of structural response, which is often carried out from both the theoretical and experimental perspectives $[6,7]$.
Normally, in engineering construction, concrete is subject to not only static loads but also dynamic loads such as seismic load, wind load, impact load, and blasting load, which are all closely related to the dynamic rate effect [8-10]. For the ordinary concrete, Sparks [11] and Bischoff [12] conducted the dynamic effect-related studies in early days and suggested that the dynamic effect had a significant influence on the stress-strain curve. Li et al. $[13,14]$ carried out a comprehensive experimental study on the dynamic effect of ordinary concrete and explained the influence of dynamic effect based on the theory of elastoplastic damage and its corresponding damage mode. In addition, Shi et al. [15] examined the dynamic effect of large aggregate concrete and wet-screened concrete. Zhang et al. and Du et al. $[16,17]$ carried out experimental research on the dynamic mechanical properties of ultra-high-performance concrete and fly ash concrete under tension and compression by adopting 
the Hopkinson bar method and proposed the corresponding dynamic constitutive model respectively based on the classic model. However, there is not yet any dynamic effect-related research on lightweight aggregate concrete from the aspect of the quantitative relationship between stress-strain curve and dynamic efficiency.

In order to investigate the dynamic effect of lightweight aggregate concrete, uniaxial compression tests under 10 selected strain rates (ranging $10^{-5} \sim 10^{-1} / \mathrm{s}$ ) were conducted. Based on the test results, the failure modes of concrete and its stress-strain curves were obtained, and the peak stress, peak strain, and elastic modulus were determined accordingly. Subsequently, quantitative analysis was carried out based on these values and available literature for ordinary concrete. Then, for the experimental data, the relationships among the strain rate, peak stress, and elastic modulus of lightweight aggregate concrete were described. Furthermore, the stress-strain curve and the effect of dynamic rate were calculated following the theory of dynamic elastoplastic damage constitutive model.

\section{Experimental Overview}

2.1. Specimen Preparation. In this research, the lightweight aggregate concrete was made of ordinary Portland cement P.O32.5, light aggregate (ceramsite with particle size between 5 and $10 \mathrm{~mm}$ ), fine aggregate (natural medium sand), and urban tap water, with a designed strength of $30 \mathrm{MPa}$. No other additive ingredients were added. The detailed composition of ingredients is listed in Table 1.

For the uniaxial compression test, the specimen was made into a cube shape with $100 \mathrm{~mm}$ in length. During the test, 10 strain rates were applied, namely, $10^{-5} / \mathrm{s}, 5 \times 10^{-5} / \mathrm{s}, 10^{-4} / \mathrm{s}$, $5 \times 10^{-4} / \mathrm{s}, 10^{-3} / \mathrm{s}, 2.0 \times 10^{-3} / \mathrm{s}, 5 \times 10^{-3} / \mathrm{s}, 10^{-2} / \mathrm{s}, 2 \times 10^{-2} / \mathrm{s}$, and $5 \times 10^{-2} / \mathrm{s}\left(10^{-5} / \mathrm{s}\right.$ indicates the static loading strain rate). The selected strain rates covered earthquake magnitude as well (usually ranging from $10^{-4} / \mathrm{s}$ to $10^{-1} / \mathrm{s}$ ). From the test, the stress strain of lightweight aggregate concrete was obtained. The strain rate loading scenarios are presented in Table 2.

2.2. Experimental Equipment. In this study, a hydraulic servo machine was used to examine the influence of strain rate on concrete. This machine consists of hydraulic actuating heads, a loading displacement acquisition system, and a medium control device, as shown in Figure 1. In addition, high precision load sensors and displacement sensors were equipped on each loading actuating head to capture the corresponding data. All the sensors met the precision requirements of the experiment.

2.3. Loading Method. In view of the purpose of this research, the lightweight aggregate concrete specimens were made into cubes with $100 \mathrm{~mm}$ in length at the required strength of $30 \mathrm{MPa}$. For the need to reduce the influence triggered by friction during the test, all the specimens were coated with three layers of polyethylene film with machinery grease. This method was widely recognized as an efficiency way to reduce friction by many scholars [15].
TABLE 1: Light aggregate concrete mix ratio.

\begin{tabular}{lcccc}
\hline \multirow{2}{*}{ Grade } & \multicolumn{4}{c}{ Mass of ingredients in each cubic meter of concrete $(\mathrm{kg})$} \\
& Cement & Water & Light aggregate & Fine aggregate \\
\hline LC30 & 460 & 170 & 670 & 650 \\
\hline
\end{tabular}

TABLE 2: Loading scenarios for uniaxial compression test.

\begin{tabular}{lccccc}
\hline Index & $\begin{array}{c}\text { Strain rate } \\
\left(\mathrm{s}^{-1}\right)\end{array}$ & Quantity & Index & $\begin{array}{c}\text { Strain rate } \\
\left(\mathrm{s}^{-1}\right)\end{array}$ & Quantity \\
\hline 1 & $1.0 \times 10^{-5}$ & 3 & 6 & $2.0 \times 10^{-3}$ & 3 \\
2 & $5.0 \times 10^{-5}$ & 3 & 7 & $5.0 \times 10^{-3}$ & 3 \\
3 & $1.0 \times 10^{-4}$ & 3 & 8 & $1.0 \times 10^{-2}$ & 3 \\
4 & $5.0 \times 10^{-4}$ & 3 & 9 & $2.0 \times 10^{-2}$ & 3 \\
5 & $1.0 \times 10^{-3}$ & 3 & 10 & $5.0 \times 10^{-2}$ & 3 \\
\hline
\end{tabular}

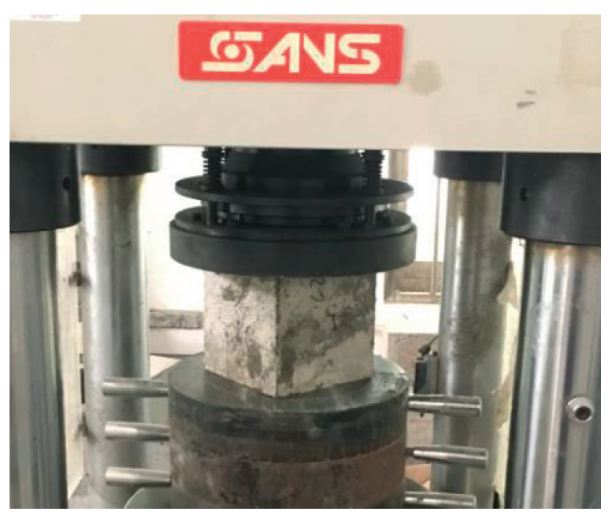

FIGURE 1: Experiment equipment.

The hydraulic servo machine was used to apply dynamic loads on lightweight aggregate concrete following different loading strain rates through the displacement control method, and the failure modes and stress-strain curves under different loading conditions were obtained. Strain gauges were used to measure the strain data and the built-in extensometer device of the test machine was used to obtain the deformation data for correction, so as to determine the final strain value of lightweight aggregate concrete during the loading process. All the deformation acquisition devices were calibrated properly before the experiment to guarantee the compliance with the measurement requirements. The stress values were determined by the load sensors that come with the testing equipment.

In order to ensure the accuracy of the test on the dynamic properties of lightweight aggregate concrete, a mixed loading method combining compression and displacement was adopted. Firstly, compressive loading was well managed to ensure the appropriateness of preloading. The value of load was increased from $0 \mathrm{MPa}$ to $0.05 f_{\mathrm{c}}$ and then decreased to $0 \mathrm{MPa}$ gradually. This process was repeated for three times. Then, the control mode was shifted to the displacement control method following the strain rates listed in Table 2, and the displacement change was initiated from $0 \mathrm{~mm}$ until the failure of the specimen. 


\section{Results and Analysis}

3.1. Failure Mode. In the research of concrete material, the damage mode analysis is very meaningful to the practical application of concrete and the corresponding structural study. Meanwhile, the damage mode analysis can also provide a reference for the examination of dynamic properties of lightweight aggregate concrete. From the experiment of this study, the failure modes of lightweight aggregate concrete under various strain rates were obtained, as shown in Figure 2.

According to Figure 2, there was a uniform crack that appeared on the loading surface of the light aggregate concrete specimen under the uniaxial static load $\left(1 \times 10^{-5} / \mathrm{s}\right)$. The failure of specimen was mainly triggered by the shear stress, which is quite different from the failure mode of ordinary concrete. In ordinary concrete, the failure of specimen mainly concentrates on the adhesive material under the uniaxial static load, while the aggregate material will not be damaged. As the loading strain rate increased, two to three main cracks began to appear in the loading zone of the specimen. With the further increase of the load, the cracks would penetrate the whole specimen and cause it to fail. The fracture of the specimen under dynamic loading mainly presented as diagonal cracks. This is consistent with the failure mode of ordinary concrete under dynamic compression. It was suggested that, due to the increase of loading strain rate, the cracks in the loading zone of lightweight aggregate concrete could not fully develop under dynamic loading as that under static loading. Instead, it might reach a uniform stress condition and result in cracks developed in a diagonal pattern. Although the failure modes for both ordinary concrete and lightweight aggregate concrete are similar under dynamic compression, it should be noticed that the failure mode of lightweight aggregate concrete is mainly caused by shear stress rather than by adhesive material failure as in ordinary concrete.

3.2. Stress-Strain Curve. Based on the dynamic properties test of lightweight aggregate concrete under uniaxial compression, the stress-strain curves for various strain rates were obtained. From the curves, the peak stress, peak strain, and elastic modulus under different strain rates were determined (Figure 3).

According to Figure 3, the stress-strain curves of lightweight aggregate concrete differed greatly under different strain rates. As the strain rate increased from $10^{-5} / \mathrm{s}$ to $5 \times 10^{-2} / \mathrm{s}$, the peak stress was increased from $23 \mathrm{MPa}$ to $36 \mathrm{MPa}$; in comparison, the peak strain and elastic modulus changed less significantly (this phenomenon would be further discussed later). It was found that the stress-strain curve had good continuity and smoothness and therefore could satisfy the basic characteristics of uniaxial compression. Besides, as the strain rate increased, the energy dissipation capacity was improved significantly. This finding is consistent with the conclusion of dynamic characteristics of ordinary concrete obtained by Zeng Shajie [11].
3.3. Peak Stress. In the study of dynamic characteristics of ordinary concrete, the peak stress is an important parameter that can be extracted from the stress-strain curve. In order to examine the influence of dynamic loading rate on the peak stress of ordinary concrete, the dynamic increase coefficient was introduced, which is expressed as follows:

$$
\alpha_{D I F}=\frac{\sigma_{d}}{\sigma_{s}},
$$

where $\sigma_{s}$ is the peak stress corresponding to the strain rate of $10^{-5} / \mathrm{s}$ and $\sigma_{d}$ is the peak stress corresponding to the strain rate of $5 \times 10^{-5} / \mathrm{s}, 10^{-4} / \mathrm{s}, 5 \times 10^{-4} / \mathrm{s}, 10^{-3} / \mathrm{s}, 2.0 \times 10^{-3} / \mathrm{s}$, $5 \times 10^{-3} / \mathrm{s}, 10^{-2} / \mathrm{s}, 2 \times 10^{-2} / \mathrm{s}$, and $5 \times 10^{-2} / \mathrm{s}$, respectively.

In this paper, the increase coefficient was introduced as well for the lightweight aggregate concrete. The peak stress values of lightweight aggregate concrete under various strain rates are listed in Table 3.

As shown in Table 3, there was a significant increase in the peak stress as the strain rate increased. When the loading strain rate reached $5.0 \times 10^{-2} / \mathrm{s}$, the value of peak stress was increased by $54.48 \%$. According to the research on the influence of uniaxial compression on the strain rate of ordinary concrete as reported by Sparks and Menzies [11] and Bischoff and Perry [12], the peak stress of ordinary concrete was increased by $40 \%$ when the strain rate reached $5.0 \times 10_{-}{ }^{2} /$ s. In the research of dynamic properties of ordinary concrete conducted by Song et al. [15], the peak stress was increased by $34.26 \%$ when the strain rate increased from $2.0 \times 10^{-5} / \mathrm{s}$ to $2.0 \times 10^{-2} / \mathrm{s}$. Furthermore, according to Li et al. [13], the peak stress was increased by $30 \%$ to $40 \%$ as the strain rate increased from $10^{-5} / \mathrm{s}$ to $10^{-2} / \mathrm{s}$. Based on these available data, it was believed that the influence of dynamic load on lightweight aggregate concrete was stronger than that on ordinary concrete.

The maximum stress increased along with the loading strain rate raising in the uniaxial compression test on lightweight aggregate concrete. This finding is consistent with the failure mechanism of ordinary concrete that the failure process will be delayed under the effect of a high strain rate. This phenomenon can result in a higher peak stress under dynamic strain rate than that under static strain rate, and the peak stress can be increased with the increase of the strain rate, which has been illustrated in Figure 2 [11].

For the purpose to quantitatively analyze the influence of strain rate on the stress of lightweight aggregate concrete, the dynamic strain rates and static strain rate were both nondimensionalized and the logarithm values were calculated. Meanwhile, the peak dynamic and static stress values were nondimensionalized as well, as shown in Figure 4.

According to Figure 4, the peak stress of lightweight aggregate concrete under various strain rates was increased with the increase of the strain rate. By combining the collected data, the logarithm between the nondimensionalized peak stress and strain rate was in a linear relationship, which can be described by $\alpha_{D I F}=0.96799+0.15566 \lg \left(\dot{\varepsilon}_{s} / \dot{\varepsilon}_{d}\right)$, where $R^{2}$ equals 0.98789 . 


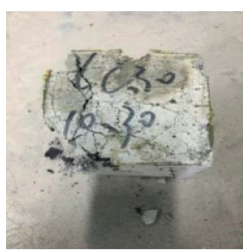

$1.0 \times 10^{-5}(\mathrm{~s})$

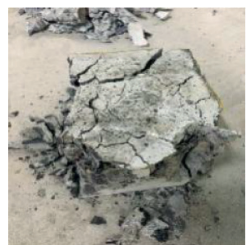

$2.0 \times 10^{-3}(\mathrm{~s})$

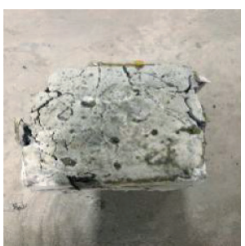

$5.0 \times 10^{-5}(\mathrm{~s})$

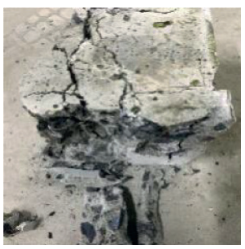

$5.0 \times 10^{-3}(\mathrm{~s})$

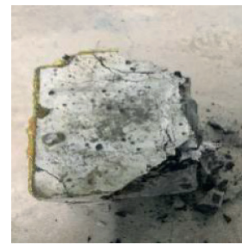

$1.0 \times 10^{-4}(\mathrm{~s})$

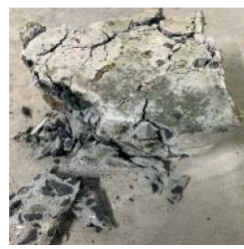

$1.0 \times 10^{-2}(\mathrm{~s})$

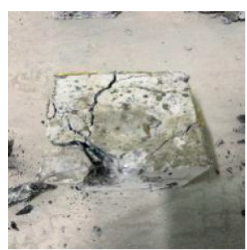

$5.0 \times 10^{-4}(\mathrm{~s})$

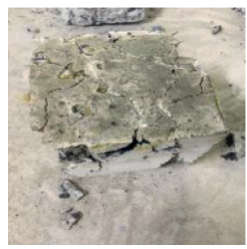

$2.0 \times 10^{-2}(\mathrm{~s})$

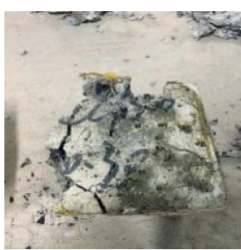

$1.0 \times 10^{-3}(\mathrm{~s})$

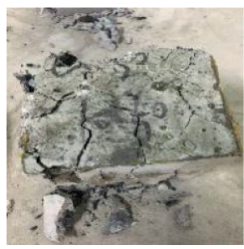

$5.0 \times 10^{-2}(\mathrm{~s})$

FIGURE 2: Failure modes of lightweight aggregate concrete under uniaxial compression at different strain rates.
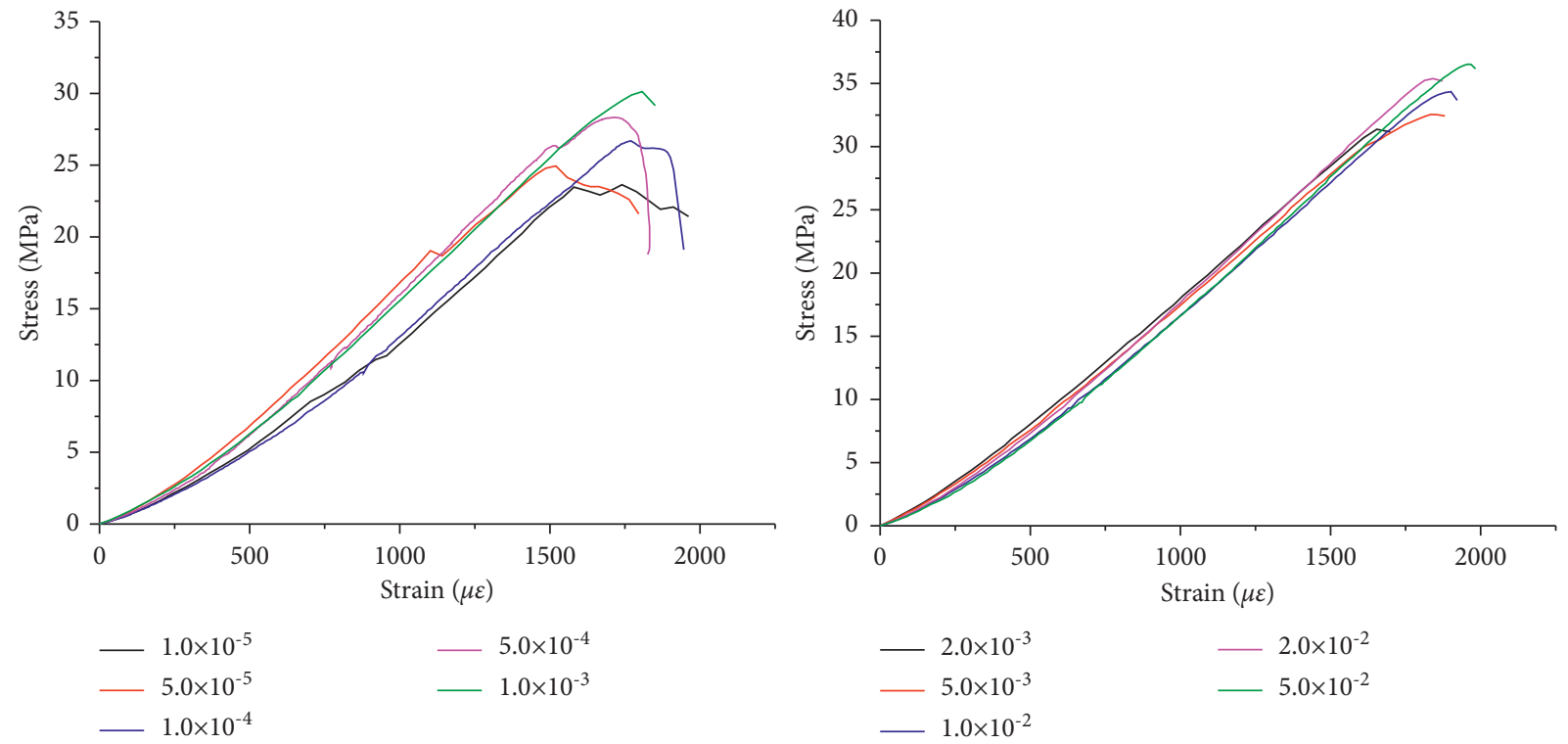

FIGURE 3: Stress-strain curves of lightweight aggregate concrete for different strain rates.

TABLE 3: The peak stress of lightweight aggregate concrete under various strain rates (MPa).

\begin{tabular}{|c|c|c|c|c|c|c|c|}
\hline Strain rate & Peak stress & $\begin{array}{c}\text { Peak stress } \\
\text { under static load }\end{array}$ & Increase coefficient (\%) & Strain rate & Peak stress & $\begin{array}{c}\text { Peak stress } \\
\text { under static load }\end{array}$ & Increase coefficient (\%) \\
\hline $1.0 \times 10^{-5}$ & 23.6393 & 23.6393 & 0 & $2.0 \times 10^{-3}$ & 31.3767 & 23.6393 & 32.73109 \\
\hline $5.0 \times 10^{-5}$ & 24.9442 & 23.6393 & 5.520045 & $5.0 \times 10^{-3}$ & 32.5385 & 23.6393 & 37.64578 \\
\hline $1.0 \times 10^{-4}$ & 26.695 & 23.6393 & 12.92636 & $1.0 \times 10^{-2}$ & 34.3465 & 23.6393 & 45.29407 \\
\hline $5.0 \times 10^{-4}$ & 28.3226 & 23.6393 & 19.8115 & $2.0 \times 10^{-2}$ & 35.3801 & 23.6393 & 49.66645 \\
\hline $1.0 \times 10^{-3}$ & 30.1226 & 23.6393 & 27.42594 & $5.0 \times 10^{-2}$ & 36.5176 & 23.6393 & 54.47835 \\
\hline
\end{tabular}

3.4. Elastic Modulus. Elastic modulus, as another important parameter that can be extracted from the stress-strain curve, plays an important role in the study of mechanical properties of concrete. In this paper, the value of elastic modulus was obtained to examine the influence of strain rate on the dynamic properties of lightweight aggregate concrete.

In order to acquire accurate elastic modulus data, the secant modulus of the $50 \%$ peak stress and $10 \%$ peak stress was used as the elastic modulus, as shown in the following equation:

$$
E=\frac{\sigma_{0.5}-\sigma_{0.1}}{\varepsilon_{0.5}-\varepsilon_{0.1}}
$$

where $\sigma_{0.5}$ and $\sigma_{0.1}$ are the $50 \%$ and $10 \%$ peak stress, respectively, and $\varepsilon_{0.5}$ and $\varepsilon_{0.1}$ are the corresponding $50 \%$ and $10 \%$ strain value, respectively. The results are shown in Table 4. 
TABLE 4: Elastic modulus of lightweight aggregate concrete under various strain rates (MPa).

\begin{tabular}{lccccccc}
\hline Strain rate & $\begin{array}{c}\text { Elastic } \\
\text { modulus }\end{array}$ & $\begin{array}{c}\text { Static } \\
\text { elastic modulus }\end{array}$ & Increase coefficient (\%) & Strain rate & $\begin{array}{c}\text { Elastic } \\
\text { modulus }\end{array}$ & Static elastic modulus & Increase coefficient (\%) \\
\hline $1.0 \times 10^{-5}$ & 1.642 & 1.642 & 0 & $2.0 \times 10^{-3}$ & 1.987 & 1.642 & 21.01096 \\
$5.0 \times 10^{-5}$ & 1.763 & 1.642 & 7.369062 & $5.0 \times 10^{-3}$ & 2.086 & 1.642 & 27.04019 \\
$1.0 \times 10^{-4}$ & 1.87 & 1.642 & 13.88551 & $1.0 \times 10^{-2}$ & 2.1 & 1.642 & 27.89281 \\
$5.0 \times 10^{-4}$ & 1.88 & 1.642 & 14.49452 & $2.0 \times 10^{-2}$ & 2.105 & 1.642 & 28.19732 \\
$1.0 \times 10^{-3}$ & 1.949 & 1.642 & 18.69671 & $5.0 \times 10^{-2}$ & 2.114 & 1.642 & 28.74543 \\
\hline
\end{tabular}

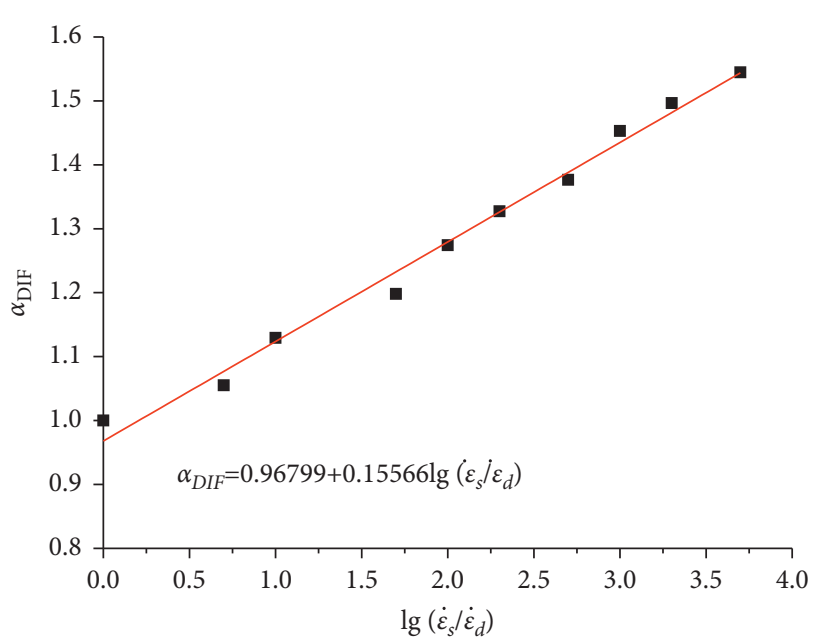

- Experimental Values

_ Linear fit of Experimental Values

Figure 4: Increase coefficient of peak stress of light aggregate concrete under different strain rates.

According to Table 4, the average elastic modulus was increased relative to the static elastic modulus with the increase of strain rate. When the strain rate reached $5.0 \times 10^{-2} / \mathrm{s}$, the elastic modulus of lightweight aggregate concrete was increased by $28.75 \%$, which was smaller than the increase in peak stress as presented in Table 4 . Therefore, it was believed that the influence of strain rate on peak stress was stronger than that on elastic modulus. In the report published by Zeng and Li [14], the elastic modulus was increased by $11.1 \%$ when the loading strain rate increased from $10^{-5} / \mathrm{s}$ to $3.5 \times 10^{-2} / \mathrm{s}$ in the dynamic properties test of ordinary concrete. It can be noticed that the dynamic load has a more significant effect on the elastic modulus of lightweight aggregate concrete than on that of ordinary concrete.

In order to quantitatively analyze the influence of loading strain rate on the elastic modulus of lightweight aggregate concrete further, the dynamic loading strain rates and static loading strain rate were nondimensionalized and their corresponding logarithm values were calculated. Meanwhile, the dynamic elastic modulus and static elastic modulus were also nondimensionalized, as shown in Figure 5.

According to Figure 5, it was found that the elastic modulus of lightweight aggregate concrete under various strain rates was increased with the increase of strain rate.
Based on the obtained experimental data, the relationship between the nondimensionalized dynamic and static strain rate can be described by $\left(E_{d} / E_{s}\right)=1.02424+$ $0.07996 \lg \left(\dot{\varepsilon}_{s} / \dot{\varepsilon}_{d}\right)$, where the relative coefficient $R$ equals 0.9423 . The elastic modulus of lightweight aggregate concrete and the logarithm of nondimensionalized dynamic or static strain rate were in a linear relationship.

The fitting slope of the equation describing the relationship between the peak stress and strain rate was equal to 0.15566. Compared with the change of the peak stress fitting equation, the change amplitude of the elastic modulus fitting equation affected by the strain rate was only $15.57 \%$. From this point of view, the strain rate has a more significant influence on the peak stress than on the elastic modulus of lightweight aggregate concrete.

3.5. Peak Strain. According to the stress-strain curve of lightweight aggregate concrete under various strain rates, the peak strain values are determined and listed in Table 5.

For ordinary concrete, there is no agreed conclusion about the influence of strain rate on the peak strain yet. However, there are currently three opinions about the effect of strain rate on ordinary concrete: (1) the peak strain of concrete increases with the increase of strain rate; (2) the peak strain of concrete does not change obviously with the increase of strain rate; (3) the peak strain of concrete decreases with the increase of strain rate [11-13].

In order to quantitatively analyze the influence of loading strain rate on the peak strain of lightweight aggregate concrete further, the dynamic strain rates and static strain rate were nondimensionalized and their corresponding logarithm values were calculated. Meanwhile, the dynamic peak strain and static peak strain are also nondimensionalized, as shown in Figure 6.

While the loading strain rate increased from $10^{-5}$ to $5.0 \times 10^{-2}$, the peak strain changed in the range from $87.36 \%$ to $112.35 \%$ of the standard value. According to Figure 6, although there were some exceptional points, the general trend of the peak strain basically increased along with the increase of the strain rate, which is agreed with the first opinion mentioned above. Besides, similar to the ordinary concrete, lightweight aggregate concrete is characterized by a typical mechanical property of randomness. Therefore, it was believed that the coupling effect of randomness and rate dependency was the main factor resulting in the irregular change of peak strain for lightweight aggregate concrete. 


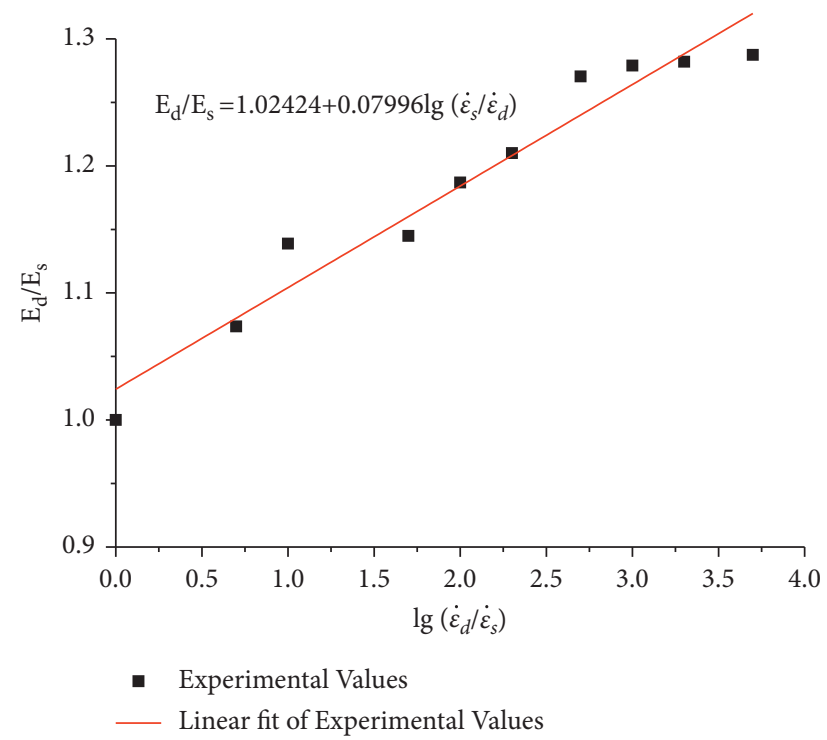

FIGURE 5: Increase coefficient of elastic modulus of lightweight aggregate concrete under different strain rates.

TABLE 5: Peak strain of light aggregate concrete under different strain rates (unit: $\mu \varepsilon$ ).

\begin{tabular}{lccccccc}
\hline Strain rate & Peak strain & $\begin{array}{c}\text { Static peak } \\
\text { strain } \times 10^{4}\end{array}$ & Increase coefficient (\%) & Strain rate & Peak strain & Static peak strain $\times 10^{4}$ & Increase coefficient $(\%)$ \\
\hline $1.0 \times 10^{-5}$ & 1740 & 1740 & 0 & $2.0 \times 10^{-3}$ & 1654 & 1740 & -4.94253 \\
$5.0 \times 10^{-5}$ & 1520 & 1740 & -12.6437 & $5.0 \times 10^{-3}$ & 1833 & 1740 & 5.344828 \\
$1.0 \times 10^{-4}$ & 1769 & 1740 & 1.666667 & $1.0 \times 10^{-2}$ & 1901 & 1740 & 9.252874 \\
$5.0 \times 10^{-4}$ & 1714 & 1740 & -1.49425 & $2.0 \times 10^{-2}$ & 1841 & 1740 & 5.804598 \\
$1.0 \times 10^{-3}$ & 1807 & 1740 & 3.850575 & $5.0 \times 10^{-2}$ & 1955 & 1740 & 12.35632 \\
\hline
\end{tabular}

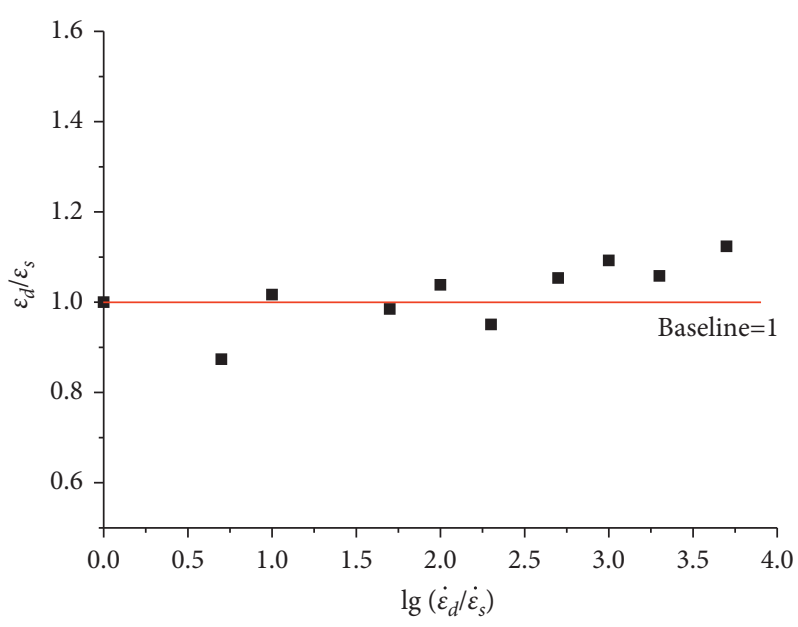

- Experimental Values

FIgURE 6: Increase coefficient of peak strain under different strain rates.

\section{Dynamic Elastoplastic Damage Constitutive Model of Lightweight Aggregate Concrete and Its Calculation}

4.1. Single-Scalar Elastoplastic Damage Constitutive Model. In the relevant literature, an energy which was based on the elastoplastic damage constitutive model under static load was proposed. It was generally believed that the single-scalar elastoplastic damage constitutive model could satisfy the requirement for describing the isotropic damage of homogeneous material, if it was not concerned with the effect of stiffness recovery under repeated loading $[13,14]$.

The materials of elastoplastic damage conform to the classical elastoplastic model in the effective stress space. 
According to the principle of equivalent strain, the following equation was established:

$$
\bar{\sigma}=E_{0}: \varepsilon^{e}=E_{0}:\left(\varepsilon-\varepsilon^{p}\right),
$$

where $\bar{\sigma}$ is the effective stress, $E_{0}$ is the elastic stiffness tensor, $\mathcal{E}^{e}$ is the elastic strain tensor, $\varepsilon^{p}$ is the plastic strain tensor, and $\varepsilon$ is the total strain tensor.

Thus, the elastoplastic damage constitutive relation of concrete was obtained as follows:

$$
\sigma=(1-d) \bar{\sigma}=(1-d) E_{0}:\left(\varepsilon-\varepsilon^{p}\right)
$$

where $d$ is the damage variable. Because the damage will lead to the degradation of the material unloading stiffness, it can be determined that $d$ ranges between 0 and 1 .

\subsection{Evolution Rule of Internal Variable}

4.2.1. Rule of Plastic Flow. Assuming that the plastic flow of damaged material occurred in the nondamaged part of concrete, the determination of the rule of plastic flow should therefore be carried out in the effective stress space. Because the plastic deformation was considered in the effective stress space, the physical meaning of the study was that the development of concrete damage affected the development of plastic deformation, which was in line with the actual situation.

For the rule of plastic strain evolution, a simplified equation without affecting the precision of calculation could be used:

$$
\begin{aligned}
& \varepsilon^{p}=b^{p} \bar{\sigma}, \\
& b^{p}=E_{0} \xi H(d) \frac{\left\langle\varepsilon^{e}: \varepsilon\right\rangle}{\bar{\sigma}: \bar{\sigma}} \geq 0,
\end{aligned}
$$

where $\xi$ is the model parameter for describing the plastic deformation of concrete under compression, which ranges between 0 and 1 ( 0 and 1 are corresponding to linear elasticity and ideal elastoplasticity, respectively. According to the relevant literature and the experimental data, it took the value of 0.2 in this study [14]. $H(\cdot)$ is the function of Heaviside, which is defined as $H(x)=\left\{\begin{array}{ll}1, & x>0 \\ 0, & x \leq 0\end{array} .\langle\cdot\rangle\right.$ is the brackets of Macaulay, which are defined as $\langle x\rangle=(x+|x| / 2)$.

4.2.2. Rule of Damage Evolution. The rate dependency effect of concrete is related to both the development of plastic deformation and damage evolution, but the latter is predominant in the rate dependency effect. In the framework of the deterministic damage mechanics, the damage internal variable $d$ can be used to expand the damage flow factor $\dot{\lambda}^{d}$, which is used to reflect the hysteresis effect of damage evolution of concrete during dynamic loading.

In the classical damage mechanics, the damage state is determined by introducing the damage potential function $G(Y, r)$, which could be defined as follows:

$$
G(Y, r)=g(Y)-g(r),
$$

where $G=0$ determines the damage surface, $g(\cdot)$ is a monotonically increasing function, and $Y$ is the damage energy release rate for concrete at the time of $t$ and can be expressed as $r=\max \left\{r_{0}, \max _{\tau \in[0, t]} Y_{\tau}\right\}$, where $r_{0}$ is the threshold of the initial damage energy release rate.

Considering the establishment of the damage criterion, only when the damage energy release rate $Y$ exceeds the threshold of the initial damage energy release rate $r_{0}$, the damage will occur. In the process of material loading at any time, if the material damage energy release rate $Y_{t}$ is higher than the historical maximum damage energy release rate $r_{t}$, the material damage will develop further, namely, in the damage loading state. Otherwise, it will be in the process of damage unloading or neutral variable loading.

According to the relevant literature, the damage energy release rate was obtained as follows:

$$
Y=\alpha \bar{I}_{1}+\sqrt{3 \bar{J}_{2}}
$$

where $\bar{I}_{1}$ and $\bar{J}_{2}$ are the first invariant of effective stress tensor $\bar{\sigma}$ and the second invariant of effective deviatory stress tensor $\bar{s}$, respectively. $\alpha$ is a constant, $\alpha=\left(\left(f_{\text {by }} / f_{y}-1\right) /\right.$ $\left.\left(2 f_{\text {by }} / f_{y}-1\right)\right)$, where $f_{\text {by }}$ is the equivalent peak strength of biaxial compression and $f_{y}$ is the peak strength of uniaxial compression. According to the relevant literature, the ratio between the biaxial and uniaxial compressive strength of the proposed model was 1.16; thus, $\alpha=0.1212[14]$.

Then, the initial elastoplastic damage energy threshold was obtained as follows:

$$
r_{0}=(1-\alpha) f_{0}
$$

where $f_{0}$ is the linear elastic limit strength under uniaxial compression, which is generally equal to $(0.3 \sim 0.5) f_{c}$, where $f_{c}$ is the uniaxial compressive strength of concrete.

The dynamic expansion of the damage energy release rate was

$$
r_{t}=\mu\left\langle\frac{Y_{t}}{r_{t}}-1\right\rangle^{n}
$$

where $Y_{t}$ is the dynamic damage energy release rate, $r_{0}$ is the threshold of the initial damage energy release rate, $r_{t}$ is the historical maximum damage energy release rate, and $\mu$ and $n$ are the dynamic effect empirical parameters.

Based on the above damage criterion and the evolution rule of damage variable, the expression of the dynamic damage evolution was obtained as follows:

$$
d=1-\frac{r_{0}}{r_{t}}(1-A)-A \exp \left[B\left(1-\frac{r_{t}}{r_{0}}\right)\right],
$$

where $A$ and $B$ are the model parameters, which can be calibrated from the stress-strain curve.

The constitutive equation is essentially a set of ordinary differential equations constrained by the Kuhn-Tucker complementary conditions, as shown in Table 6. In this 
TABLE 6: Plastic and damage evolution equations.

\begin{tabular}{lc}
\hline Plastic evolution equations & Damage evolution equations \\
\hline$\dot{\varepsilon}=\dot{\lambda}^{\mathrm{p}} \partial_{\bar{\sigma}} F^{\mathrm{p}}$ & $\dot{d}^{ \pm}=\dot{\lambda}^{d \pm}\left(\partial g^{ \pm}\left(Y^{ \pm}\right) / \partial Y^{ \pm}\right)$ \\
$\dot{\kappa}=\dot{\lambda}^{\mathrm{p}} \mathbf{H}$ & $\dot{\lambda}^{d \pm}=\dot{r}^{ \pm}$ \\
$F(\bar{\sigma}, \kappa) \leq 0 ; \dot{\lambda}^{\mathrm{p}} \geq 0 ; \dot{\lambda}^{\mathrm{p}} F(\bar{\sigma}, \kappa) \leq 0$ & $\dot{\lambda}^{d \pm} \geq 0 ; \bar{G}^{ \pm}\left(Y^{ \pm}, r^{ \pm}\right) \leq 0 ; \dot{\lambda}^{d \pm} \bar{G}^{ \pm}\left(Y^{ \pm}, r^{ \pm}\right)=0$ \\
\hline
\end{tabular}

TABLE 7: Numerical implementation of the dynamic plastic damage model based on the return-mapping algorithm.

\begin{tabular}{|c|c|c|}
\hline Elastic-predictor & Plastic-corrector & Damage-corrector \\
\hline$\dot{\varepsilon}=\nabla^{S} \dot{u}(t)$ & $\dot{\varepsilon}=0$ & $\dot{\varepsilon}=0$ \\
\hline$\dot{\varepsilon}^{\mathrm{p}}=0$ & $\dot{\mathcal{E}}^{\mathrm{p}}= \begin{cases}\dot{\lambda}^{\mathrm{p}} \partial_{\bar{\sigma}} F^{\mathrm{p}} & \text { if } F=\dot{F}=0 \\
0 & \text { otherwise }\end{cases}$ & $\dot{\varepsilon}^{\mathrm{p}}=0$ \\
\hline $\begin{array}{l}\dot{\kappa}=\dot{\lambda}^{\mathrm{p}} \mathbf{H} \\
\dot{\bar{\sigma}}=\mathbf{C}_{0}: \dot{\varepsilon}\end{array}$ & $\begin{array}{c}\dot{\varepsilon}^{\mathrm{p}}=\dot{\lambda}^{\mathrm{p}} \mathbf{H} \\
\dot{\bar{\sigma}}=-\mathbf{C}_{0}: \dot{\varepsilon}^{\mathrm{p}}\end{array}$ & $\begin{array}{l}\dot{\kappa}=0 \\
\dot{\bar{\sigma}}=0\end{array}$ \\
\hline$\dot{d}^{ \pm}=0$ & $\dot{d}^{ \pm}=0$ & $\dot{d}^{ \pm}=\left\{\dot{r}^{ \pm} h^{ \pm} \quad\right.$ if $\bar{G}^{ \pm}=\dot{\bar{G}}^{ \pm}=00$ otherwise \\
\hline $\begin{array}{l}\dot{r}^{ \pm}=0 \\
\dot{\sigma}=(\mathbf{I}-\omega): \mathbf{C}_{0}: \dot{\varepsilon}\end{array}$ & $\begin{array}{c}\dot{r}^{ \pm}=0 \\
\dot{\sigma}=-(\mathbf{I}-\omega): \mathbf{C}_{0}: \dot{\varepsilon}\end{array}$ & 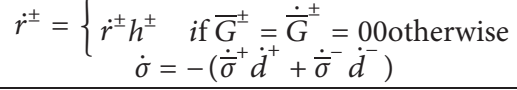 \\
\hline
\end{tabular}

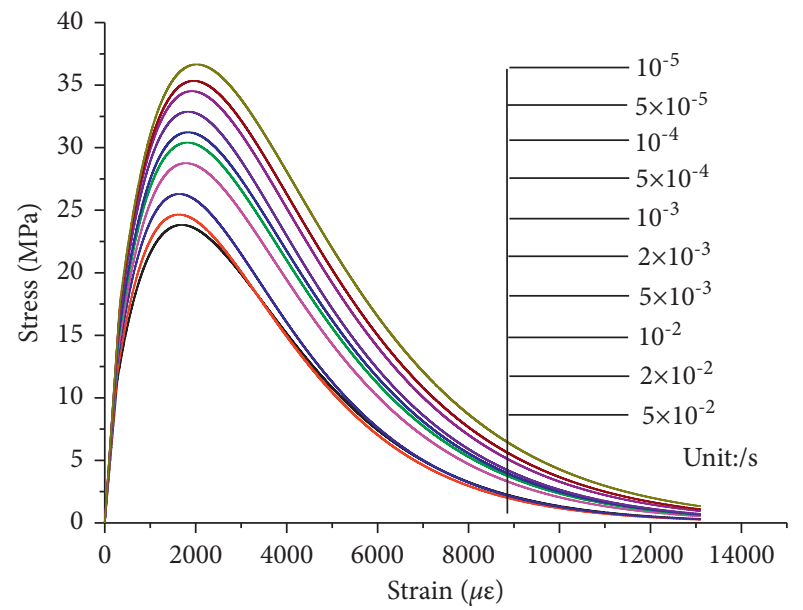

FIGURE 7: Simulation curves of light aggregate concrete under different strain rates following the stress-strain relationship.

paper, the constitutive equations of the proposed model were solved by the classical return-mapping algorithm, which has been developed and widely used to solve the (dynamic) plastic damage models of concrete [18-20]. In this algorithm, the differential equations are first discretized into the algebraic equations, and the Kuhn-Tucker complementary conditions are addressed by the operator splitting technique composed of the elastic elastic-predictor, plastic-corrector, and damage-corrector, as shown in $\mathrm{Ta}$ ble 7 . Then, the nonlinear algebraic equations are solved by the classical Newton method.

4.3. Applied Calculation. For the purpose of verifying the functionality of the constitutive model, numerical calculations of lightweight aggregate concrete under various strain rates were carried out. In the calculations, the elastic

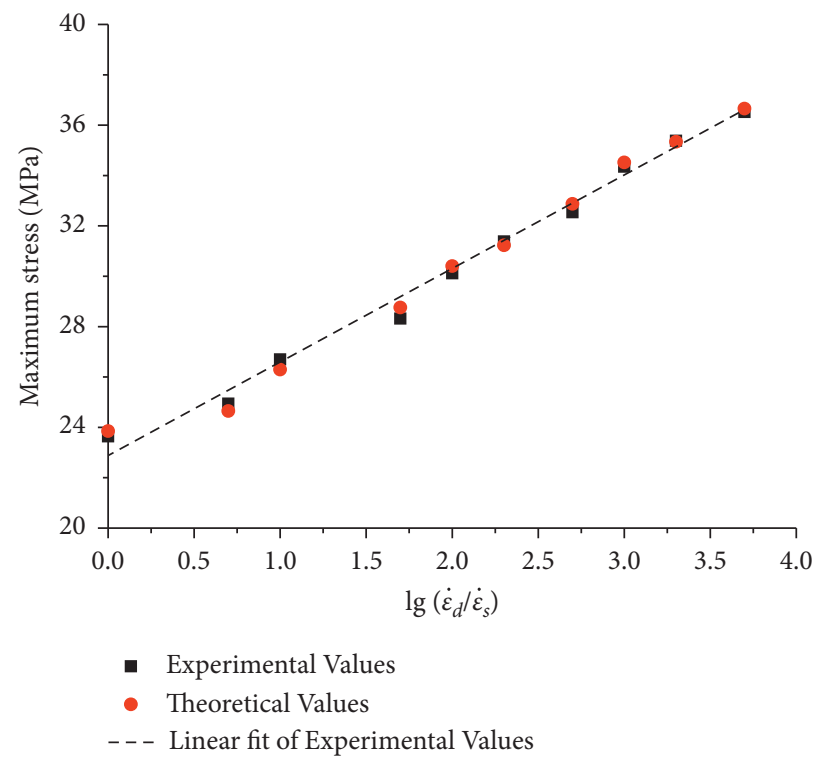

FIgURE 8: Comparison and analysis of uniaxial compressive strength of light aggregate concrete under different strain rates.

modulus $E_{0}$ was set to $1.642 \times 10^{4} \mathrm{MPa}$, the Poisson ratio was set to 0.26 , the static uniaxial compressive strength was set to 23.64 MPa, notation A was set to 1.0 , notation $\mathrm{B}$ was set to 0.21 , and the values of the rest parameters were determined as described above.

According to Figure 7, the elastoplastic damage constitutive model could well describe the strain rate effect of lightweight aggregate concrete. As the strain rate increased, the peak stress of lightweight aggregate concrete was increased gradually as well. Further, Figure 8 shows that the proposed dynamic elastoplastic damage constitutive model was consistent with the peak stress obtained from the experiment. 
It should be noted that the model presented in this paper was developed on the basis of the work by Li and his coworkers $[20,21]$. The ability of the model to capture the damage law of ordinary concrete stiffness was already fully verified in the literature [20]. However, there is no report on the cyclic loading test of lightweight aggregate concrete yet, so it is difficult to directly evaluate the prediction ability of the model to the damage behavior of lightweight aggregate concrete stiffness. Therefore, the research on the damage behavior of lightweight aggregate concrete mainly focused on the damage and failure mode of lightweight concrete under dynamic loading through experiment, as shown in Figure 2. In the follow-up study, the cyclic loading test of lightweight aggregate concrete will be explored to further verify the prediction ability of the model to the stiffness damage behavior.

\section{Conclusions}

The experiment on the dynamic properties of lightweight aggregate concrete was conducted based on 10 selected strain rates (ranging from $10^{-5}$ to $10^{-1} / \mathrm{s}$ ). By performing uniaxial compression test on the lightweight aggregate concrete, the stress-strain curves and failure modes were obtained, and the influence of strain rate on the peak stress, peak strain, and elastic modulus was analyzed accordingly. Then, findings on lightweight aggregate concrete were compared with the relevant literature on the dynamic properties of ordinary concrete. Subsequently, the dynamic rate effect of lightweight aggregate concrete was verified using the dynamic elastoplastic damage constitutive model, and the following conclusions were drawn:

(1) The failure modes of lightweight aggregate concrete and ordinary concrete were similar when they were under static loading. The damage mode developed to oblique directional cracks as the load changed from static to dynamic. However, it should be noticed that the damage in ordinary concrete belonged to bonding material failure while the damage in lightweight aggregate concrete belonged to shear failure.

(2) With the increase of strain rate, the peak stress and elastic modulus of lightweight aggregate concrete were increased by $54.48 \%$ and $28.75 \%$, respectively. Their development trends were similar to those of ordinary concrete, but the influence on lightweight aggregate concrete was greater than that on ordinary concrete.

(3) According to the experimental data, it was found that the algorithm between nondimensionalized maximum stress and elastic modulus of lightweight aggregate concrete and loading strain rate was in linear shape.

(4) It was believed that the dynamic rate effect on lightweight aggregate concrete could be well simulated by the elastoplastic damage constitutive model.

\section{Data Availability}

The data used to support the findings of this study are available from the corresponding author upon request.

\section{Conflicts of Interest}

The authors declare that they have no conflicts of interest.

\section{Acknowledgments}

This work was supported by the Natural Science Research Institute of Colleges and Universities of Jiangsu Province General Items (20KJD560001) and Research project of Suzhou Gaobo Software Technology Vocational College (GIST2018-14). The authors gratefully acknowledge the financial support.

\section{References}

[1] Z. Guo, Strength and Deformation of concrete: Experimental Basis and Constitutive Relation, Tsinghua University press, Beijing, China, 1997.

[2] T. Hatano, H. Tsutsumi, T. Hatano, and H. Tsutsumi, "Dynamical compressive deformation and failure of concrete under earthquake load," Transactions of the Japan Society of Civil Engineers, vol. 1960, no. 67, pp. 19-26, 1960.

[3] S. Shang and Y. Song, "Dynamic biaxial tensile-compressive strength and failure criterion of plain concrete," Construction and Building Materials, vol. 40, no. 40, pp. 322-329, 2013.

[4] L. Chen, C. Yue, and L. Long, "etc. The mechanical properties of high performance lightweight aggregate concrete," Journal of Ceramics, vol. 34, no. 10, pp. 2822-2828, 2015.

[5] A. A. Hilal, N. H. Thom, and A. R. Dawson, "Failure mechanism of foamed concrete made with/without additives and lightweight Aggregate," Journal of Advanced Concrete Technology, vol. 14, no. 9, pp. 511-520, 2016.

[6] S. Gohari, S. Mouloodi, F. Mozafari et al., "A new analytical solution for elastic flexure of thick multi-layered composite hybrid plates resting on Winkler elastic foundation in air and water," Ocean Engineering, vol. 235, no. 9, Article ID 109372, 2021.

[7] A. A. Katsamakas, V. K. Papanikolaou, and G. E. Thermou, "A FEM-based model to study the behavior of SRG-strengthened R/C beams," Composite Structures, vol. 266, Article ID 113796, 2021.

[8] L. Shi, L. Wang, Y. Song, and L. Shen, "Dynamic multiaxial strength and failure criterion of dam concrete," Construction and Building Materials, vol. 66, no. 1, pp. 181-191, 2014.

[9] P. Lu and Y. Song, "Dynamic compression test of concrete and its constitutive model," Ocean Engineering, vol. 20, no. 2, pp. 43-48, 2002.

[10] S. Xiao, L. Gao, J. Lu, and Z. Wang, "Effect of strain rate on compressive behavior of concrete," Journal of Harbin University of Architecture, vol. 35, no. 5, pp. 35-39, 2002.

[11] J. B. Menzies and P. R. Sparks, "The effect of rate of loading upon the static and fatigue strengths of plain concrete in compression*," Magazine of Concrete Research, vol. 25, no. 83, pp. 73-80, 1973.

[12] P. H. Bischoff and S. H. Perry, "Compressive behaviour of concrete at high strain rates," Materials and Structures, vol. 24, no. 6, pp. 425-450, 1991.

[13] J. Li, Y. Xiao, and X. Ren, "Under different loading rates under uniaxial compression test on large sample properties of concrete," Journal of Building Structures, vol. 37, no. 8, pp. 66-75, 2016. 
[14] S. Zeng and J. Li, "Study on full curve of concrete under uniaxial compression," Journal of Tongji University, vol. 41, no. 1, pp. 7-10, 2013.

[15] L. Shi, Y. Song, and S. Lu, "Experimental study on uniaxial compression of large aggregate and wet screen concrete under different strain rates," World Seismic Engineering, vol. 32, no. 2, pp. 270-276, 2016.

[16] H. Zhang, L. Bai, Y. Qi, H. Hong, A. Neupane, and Q. Pan, "Impact of splitting tensile properties and dynamic constitutive model of fly ash concrete," Journal of Materials in Civil Engineering, vol. 32, no. 8, Article ID 04020225, 2020.

[17] Y. Du, J. Wei, K. Liu, D. Huang, Q. Lin, and B. Yang, "Research on dynamic constitutive model of ultra-high performance fiber-reinforced concrete," Construction and Building Materials, vol. 234, Article ID 117386, 2020.

[18] J. C. Simo and T. J. Hughes, Computational Inelasticity, Springer Science \& Business Media, New York, 2006.

[19] J. Lee and G. L. Fenves, "Plastic-damage model for cyclic loading of concrete structures," Journal of Engineering $\mathrm{Me}$ chanics, vol. 124, no. 8, pp. 892-900, 1998.

[20] X. Ren and J. Li, "A unified dynamic model for concrete considering viscoplasticity and rate-dependent damage," International Journal of Damage Mechanics, vol. 22, no. 4, pp. 530-555, 2013.

[21] J. Y. Wu, J. Li, and R. Faria, "An energy release rate-based plastic-damage model for concrete," International Journal of Solids and Structures, vol. 43, no. 3-4, pp. 583-612, 2006. 